\title{
Fatal neonatal hypertrophic cardiomyopathy caused by compound heterozygous truncating MYBPC3 mutation
}

\author{
S. Alsters · L. Wong · L. Peferoen · H. W. M. Niessen · H. Bikker · M. W. Elting · A. C. Houweling
}

Published online: 11 February 2019

(C) The Author(s) 2019

We report the clinical and genetic findings of a previously healthy girl who died suddenly at the age of 9 weeks. Severe cardiac enlargement was observed on post-mortem MRI (Fig. 1a) and at autopsy. Cardiomyocyte disarray was observed with distinct (peri)nuclear changes consistent with hypertrophic cardiomyopathy (HCM), by light microscopy (Fig. 1b). No signs of mitochondrial or storage diseases were seen by electron microscopy (not shown). There was no history of maternal diabetes mellitus and family history was negative for sudden death, cardiomyopathy or heart failure. DNA testing revealed compound heterozygous truncating MYBPC3 mutations: c.2373dup p.(Trp792Valfs*41), inherited from the mother, and c.2827C>T p.(Arg943*), inherited from the father. Both are Dutch founder mutations and are, in a heterozygous state, the most common causes of (adult onset) HCM in the Netherlands [1]. Identification of these pathogenic mutations not only explained the neonatal onset of HCM in the index, but also allowed for the screening of other relatives at risk for (adult onset) HCM. Fatal neonatal HCM caused by homozygous or compound heterozygous pathogenic

\footnotetext{
S. Alsters $\cdot$ M. W. Elting $\cdot$ A. C. Houweling $(\bowtie)$

Department of Clinical Genetics, Amsterdam UMC, Vrije

Universiteit Amsterdam, Amsterdam, The Netherlands

a.houweling@vumc.nl

L. Wong

Department of Cardiology, Amsterdam UMC, Vrije

Universiteit Amsterdam, Amsterdam, The Netherlands

L. Peferoen · H. W. M. Niessen

Department of Pathology, Amsterdam UMC, Vrije

Universiteit Amsterdam, Amsterdam, The Netherlands

H. Bikker

Department of Clinical Genetics, Amsterdam UMC, Academic Medical Center, Amsterdam, The Netherlands
}

mutations in one of the sarcomeric protein encoding genes is thought to be rare, but the exact prevalence is unknown [2-5]. Although other causes of neonatal cardiac hypertrophy must be considered (such as maternal diabetes, RASopathies, mitochondrial or storage disorders), we believe this case underlines the value of testing for genetic causes of HCM.

Conflict of interest S. Alsters, L. Wong, L. Peferoen, H.W.M. Niessen, H. Bikker, M.W. Elting and A.C. Houweling declare that they have no competing interests.

Open Access This article is distributed under the terms of the Creative Commons Attribution 4.0 International License (http://creativecommons.org/licenses/by/4.0/), which permits unrestricted use, distribution, and reproduction in any medium, provided you give appropriate credit to the original author(s) and the source, provide a link to the Creative Commons license, and indicate if changes were made.

\section{References}

1. Christiaans I, Nannenberg EA, Dooijes D, et al. Founder mutations in hypertrophic cardiomyopathy patients in the Netherlands. Neth Heart J.2010;18:248-54.

2. Wessels MW, Herkert JC, Frohn-Mulder IM, et al. Compound heterozygous or homozygous truncating MYBPC3 mutations cause lethal cardiomyopathy with features of noncompaction and septal defects. Eur J Hum Genet. 2015;23:922-8.

3. Xin B, Puffenberger E, Tumbush J, et al. Homozygosity for a novel splice site mutation in het cardiac myosin-binding protein $C$ gene causes severe neonatal hypertrophic cardiomyopathy. Am J Med GenetA. 2007;143A:2662-7.

4. Zahka K, Kalidas K, Simpson MA, et al. Homozygous mutation of MYBPC3 associated with severe infantile hypertrophic cardiomyopathy at high frequency among the Amish. Heart. 2008;94:1326-30.

5. Lekanne Deprez RH, Muurling-Vlietman JJ, Hruda J, et al. Two cases of severe neonatal hypertrophic cardiomyopathy caused by compound heterozygous mutations in the MYBPC3 gene. J Med Genet. 2006;43:829-32. 
Fig. 1 a Post-mortem MRI showing severe cardiac enlargement. b Light microscopy displaying cardiomyocyte disarray with distinct (peri)nuclear changes consistent with hypertrophic cardiomyopathy. HE Haematoxylin and eosin stain
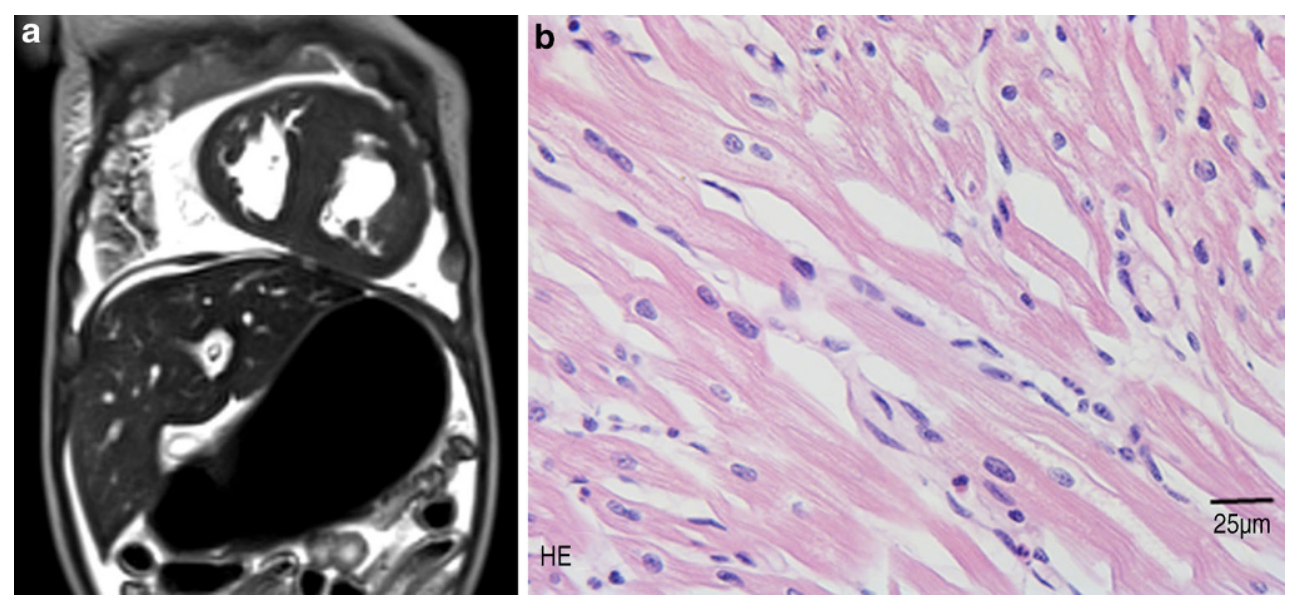